\title{
Francisco de Goya y Lucientes: «Aún aprendo»
}

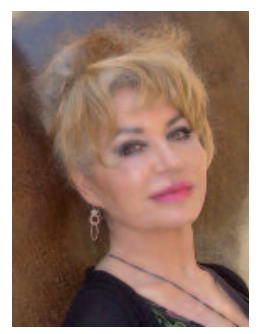

Aurora Guerra-Tapia

Profesora titular de Dermatología. Departamento de Medicina.

Facultad de Medicina. Universidad Complutense de Madrid.

Jefa de la Sección de Dermatología. Hospital Universitario 12 de Octubre. Madrid. Profesora de Dermatología. Universidad Internacional de La Rioja (UNIR).
Los lienzos y cartones que conforman la obra del extraordinario pintor espanol retratan la sociedad de su tiempo en muchos más aspectos de los percibidos en una primera impresión. Así sucede en La boda (fig. 1), cuadro

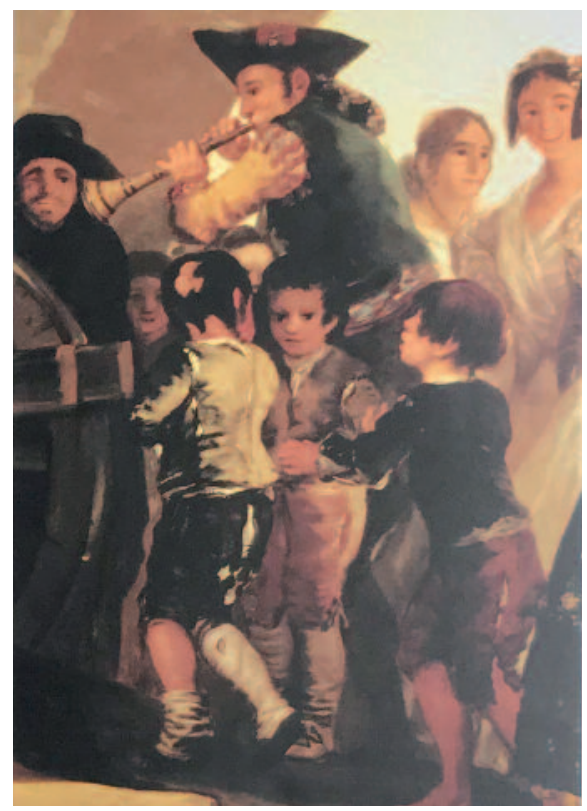

Figura 1. La boda (detalle). Francisco de Goya (1792). Tomada de: Las enfermedades de la piel en la pintura (1999), de Aurora Guerra-Tapia. Editorial You\&Us. Se advierte la zona de alopecia probablemente debida a una tiña tonsurante microscópica.
«Ni vista, ni pulso, ni pluma, ni tintero. Todo me falta y solo la voluntad me sobra».

(De la carta a Joaquín María Ferrer. 20 de diciembre de 1825)

FRANCISCO DE GOYA

(1746-1828)

expuesto en el Museo del Prado, perteneciente a la cuarta serie de cartones de la Real Fábrica de Tapices de Santa Bárbara. Uno de los niños del cortejo callejero que acompaña a los novios muestra en su cabeza una zona carente de pelo. La calva policíclica, de color grisáceo, probablemente cubierta de escamas y presente en la cabeza de un prepúber, que carece aún de la resistencia antifúngica del sebo impulsado por las hormonas masculinas, sugiere el diagnóstico de tiña tonsurante de cuero cabelludo (tinea capitis), producida por un hongo dermatofito, probablemente del género Microsporum. Dermatosis por hongos esta, nada extraña en el contexto social que representa la obra.

No menos expresivos son sus cuadernos de dibujos en los que se reflejan los grandes temas presentes en la vida de Goya: la amistad y el cariño; la violencia, consustancial con el ser humano y, en especial, contra las mujeres; la ignorancia, progenitora de los graves errores humanos; y la senectud, premonitora de la muerte e inductora de incapacidades. En todos, tan importante es el trazo como 
el título, que él mismo añade al pie, y que trasciende más allá de la imagen.

Uno de los más sutiles, exponente de su lucha interior frente a la vejez, es el que dice «Aún aprendo» ${ }^{1}$. El dibujo, realizado cuando contaba la edad de 80 años, forma parte del Álbum de Burdeos y representa a un anciano de encrespada cabellera y abundante barba blanca apoyado en sendos bastones, con los que aprende a andar como lo hace un niño. Sus dedos aparecen deformados por la artrosis. Sus ojos, de párpados arrugados y flácidos, miran penetrantemente y con cierta lateralidad, cargados, no obstante, de fuerza y determinación. Muchos estudiosos han querido ver en el protagonista un simbólico autorretrato del pintor o, más bien, de la voluntad inextinguible de desarrollo personal que mantuvo hasta los últimos momentos de su vida: «Aún aprendo» es una categórica declaración de intenciones.

Pero la vejez preocupa a Goya mucho antes de intuir sus minusvalías. En una carta escrita a su amigo de la infancia Martín Zapater el 28 de noviembre de 1787, dice ${ }^{2}$ : «Me he vuelto viejo con muchas arrugas, que no me conocerías... Lo cierto es que ya voy notando mucho los 41 ».

Los dermatólogos consideramos que el envejecimiento cutáneo comienza a hacerse patente a partir de los 35 años, con mayor o menor intensidad en función de los factores genéticos y del modo de vida de cada individuo. Goya se preocupa por las arrugas a los 41 años. Poco podía hacer. Sin embargo, si hubiese vivido en el siglo XxI, podría haberse acogido a las múltiples herramientas con las que contamos en la actualidad para prevenir o, incluso, revertir el envejecimiento de la piel. ¿Habrían sido otros sus dibujos? Sin duda. Pero no así sus títulos, que podrían mantenerse sin resultar anacrónicos: «Sueño de la mentira y la inconstancia», «Brujas disfrazadas en físicos comunes», «El sueño de la razón produce monstruos», «Yo lo vi», «Duro es el paso», «Mal marido», «Tanto ignorante pretendidamente sabio», «Animal de letras», etc.

Notario de la vida, desasosegador y apasionado. Mi devoción por Goya me ha llevado a recrear a mi estilo algunas de sus obras, para tenerle cerca, en mi museo interior, y admirarle constantemente (figs. 2 y 3 ).

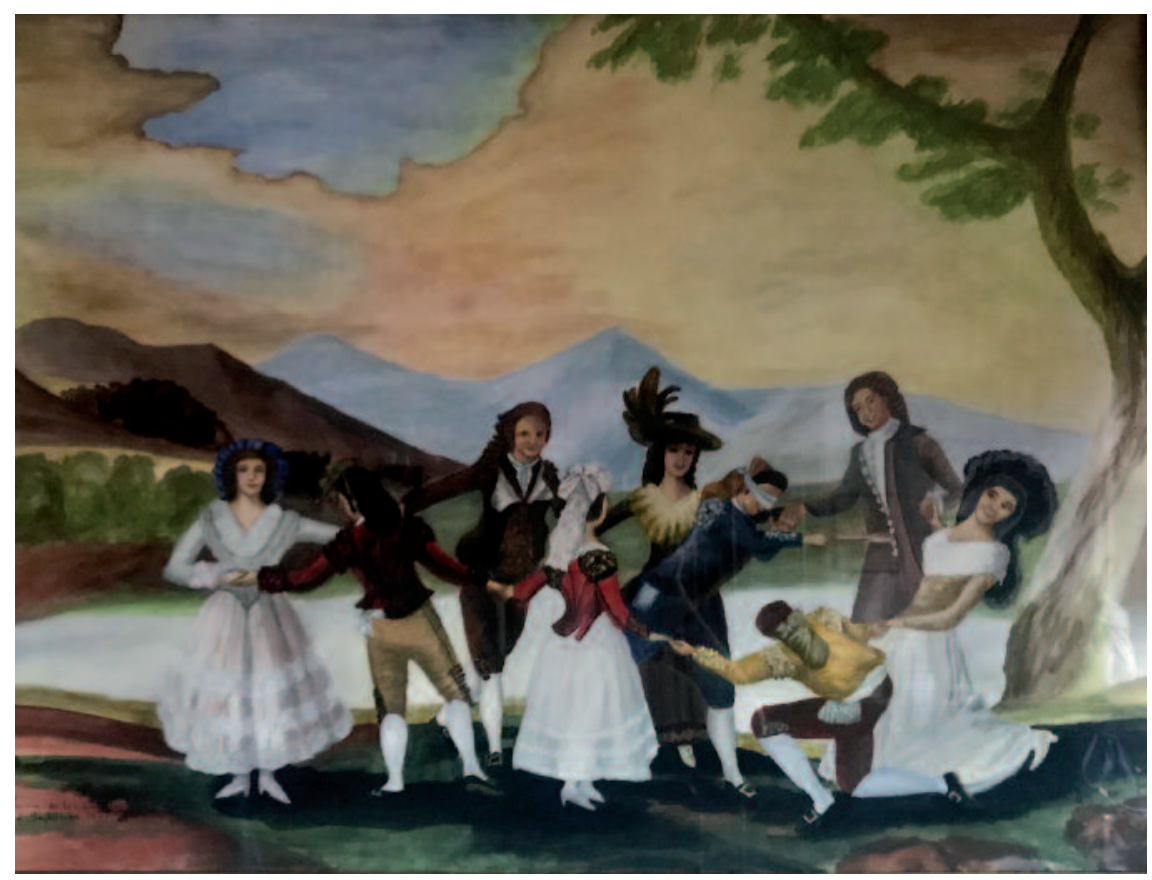

Figura 2. La gallina ciega Versión de la obra de Goya; acuarela de Aurora GuerraTapia. 
\begin{tabular}{l|l} 
el beso de la mariposa & Francisco de Goya y Lucientes: «Aún aprendo»
\end{tabular}

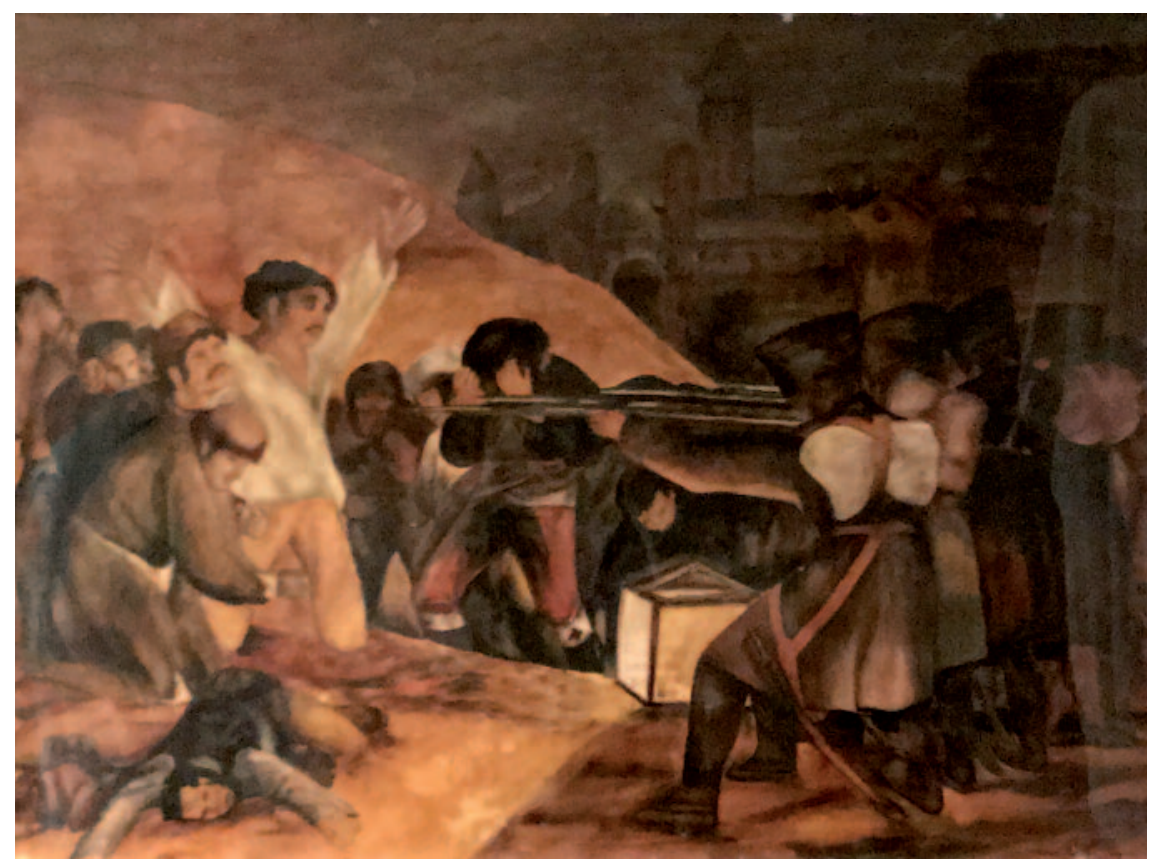

Figura 3. El 3 de mayo en Madrid o Los fusilamientos. Versión de la obra de Goya; acuarela de Aurora Guerra-Tapia.

\section{BIBLIOGRAFÍA}

1. Reproducciones. Impresión a la carta. Álbum: Aún aprendo. Francisco de Goya y Lucientes. Museo del Prado. Tienda Prado. Disponible en: http://www.tiendaprado.com/es/impresiona-la-carta/5471-album-g-aun-aprendo-290189.html [Consultado: 1 de diciembre de 2019].

2. Documentos. Cartas a Martín Zapater. Carta a Martín Zapater de 9 de julio de 1783. Goya en el Prado. Disponible en: https://www.goyaenelprado.es/obras/ficha/goya/carta-a-martin-zapater-de-9-de-julio-de-

1783/?tx_gbgonline_pi $1 \% 5$ Bgocollectionids\%5D=32\&tx_gbgo nline_pi $1 \% 5$ Bgosort $\% 5 \mathrm{D}=\mathrm{b}$ [Consultado: 1 de diciembre de 2019]. 